\title{
Introduetion of rapid response teams in Poland
}

Wojciech Szczeklik1, Jakub Fronczek1, Jacek Górka', Aleksandra Banaszewska², Piotr Gałkin³,

Waldemar Goździk4', Bartosz Kudliński', Halina Kutaj-Wąsikowska², Kamil Polok1, Anna Włudarczyk', Maria Nowina-Konopka ${ }^{6}$, Aleksandra Wołk-Popielska ${ }^{7}$, Roman Jaeschke $^{8}$

${ }^{1}$ Department of Intensive Therapy and Perioperative Medicine, Collegium Medicum, Jagiellonian University, Krakow, Poland

${ }^{2}$ Centre for Quality Monitoring in Health Care, Krakow, Poland

${ }^{3}$ Department of Anaesthesiology and Intensive Therapy, J. Śniadecki Regional Hospital in Białystok, Poland

${ }^{4}$ Department of Anaesthesiology and Intensive Therapy, Wrocław Medical University, Poland

${ }^{5}$ Department of Teaching Anaesthesiology and Intensive Therapy, Poznan University of Medical Sciences, Poland

'Institute of Journalism, Media and Social Communication, Faculty of Management and Social Communication, Jagiellonian

University, Krakow, Poland

${ }^{7}$ Medicine in Practice, Krakow, Poland

${ }^{8}$ Department of Medicine, McMaster University, Hamilton, ON, Canada

In 2016, the Polish National Center for Quality Assessment in Health Care began implementing the project on "Rapid Response Teams" (RRTs), in which 25 Polish hospitals were involved. The introduction of RRTs to the hospitals aims to improve the safety and quality of health care delivered to patients. Its main goals are: early identification of patients at risk of sudden health condition deterioration or cardiac arrest as well as quick determination and implementation of a suitable management strategy. The theoretical framework of the RRT system was described in a series of reports available on the official website of the project: http://zwr.cmj.org.pl.

During the first half of 2018, trainings were initiated; in the successive months, the RRTs formally started their activities in the hospitals involved. Throughout the period of implementation, the participants, the training team and the management team shared their observations and experience during visits to the centres engaged and during teleconferences. The seminars organised between January 31, 2019 and February 1, 2019 in Krakow were the climax of the pilot stage; the leaders of all 25 teams participated in the discussions summarising the experience gained at the advanced stage of the project implementation. The present paper discusses the practical observations made during those meetings, which could prove useful for the hospitals already involved and those planning to join the project.

\section{THE MANAGEMENT SYSTEMS APPLIED TO DATE IN CASES REQUIRING INTERVENTIONS OF ANAESTHETISTS AND INTENSIVISTS OUTSIDE OPERATING ROOMS SUITES AND INTENSIVE CARE UNITS}

Predictable situations:

- qualification for elective procedures,

- anaesthesia for elective procedures (e.g. cardioversion, endoscopy).
Unpredictable situations:

- sudden cardiac and respiratory arrest,

- anaesthesia for emergency (non-elective) procedures,

- minor procedures, e.g. implantation of central venous catheters,

- transportation of severely ill patients,

- consultations of patients whose conditions have suddenly deteriorated.

At present, depending on the medical indications and organisational strategies accepted in the individual hospitals, the above tasks belong to the responsibilities of physicians providing interventions, resuscitation teams or are performed during anaesthetic consultations. One of the consequences of introducing the RRT as a separate structure, focused on early identification and intervention in deteriorating patients, is the systematisation of activities of intensivists in non-intensive care unit (non-ICU) wards.

The individual aspects of RRT functioning are discussed below - from danger recognition, through communication, to interventions to be delivered. Moreover, based on our earlier experience, an attempt is made to indicate the directions of future activities concerning the issues heatedly debated during meetings.

\section{EARLY IDENTIFICATION OF PATIENTS AT RISK OF SUDDEN DETERIORATION OF HEALTH OR CARDIAC ARREST}

The hospitals participating in the project introduced the system of early identification of danger based on one of the two available options: (1) the "on demand" model, i.e. the staff responds to the observed and reported changes in the patient's clinical condition (the symptomatic scale based on the rule of "all or nothing") or (2) systematic screening of all patients hospitalised in the selected pilot wards 
using the National Early Warning Score (NEWS) 2 (Figure 1) [1]. The majority of hospitals decided to introduce the first option involving simple calling criteria based on abnormalities in basic measurements of vital signs (Figures 2 and 3 ).

The NEWS2 was introduced only in a few hospitals, which was mainly associated with additional workload for nurses and too few monitored hospital beds in non-ICU wards (essential for proper application of this tool). The relevant assets of the NEWS include the possibility to carry out standardised assessment of the patient's condition, early identification of sudden health deterioration, observation of its time-related changeability and adjustment of the intensity of interventions to the obtained outcome. Moreover, the above scale necessitates the regularity of measurements and provides nurses with the objective basis for informing the physician that some intervention is required, which may help to overcome possible communication barriers.

Irrespective of the way of RRT calling, the proper functioning of the system depends on adequately early detection of deteriorating patients, in which the role of nurses is pivotal. Some hospitals have suggested the strategy of active identification of higherrisk patients during routine ward rounds or duties (of physicians and nurses). We believe that such a so- lution could be useful in hospitals which have not introduced the NEWS 2 or other standardised methods of early detection of health deterioration.

Based on the experience gained by the countries which have implemented similar solutions in recent years, gradual replacement of the symptomatic scale with more advanced tools (point scales, track \& trigger monitoring systems) should be expected over time [2]. A reasonable compromise at the early stage of RRT adoption would be to focus on staff education, to sensitise all hospital healthcare providers to the alarming symptoms and to use a wide range of calling criteria, facilitating the implementation of this novel system. Furthermore, the motto "no call is a bad call" should be continuously repeated - the staff's concern about the patient's condition should be sufficient to activate the RRT [3]. Our observations have proven that "unnecessary calls" are relatively rare.

\section{Conclusions}

1. During the implementation stage, the majority of hospitals decided to introduce the zero-one system of early activation of the RRT, based on detection of alarming clinical symptoms (e.g. confusion, fever, tachycardia).

2. The key role in early identification of deteriorating patients is played by the nursing staff.

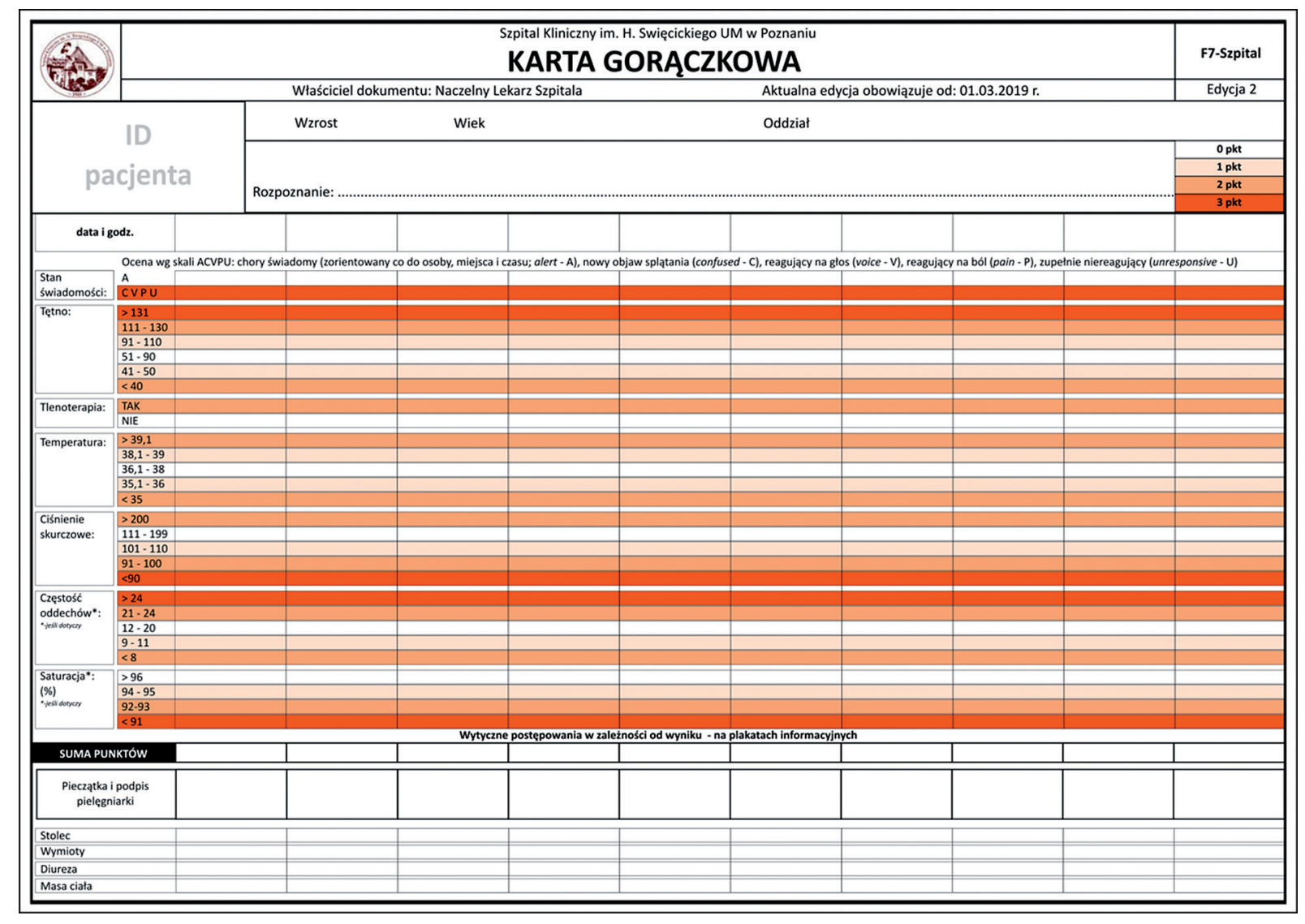

FIGURE 1. A temperature chart template based on the National Early Warning Score (NEWS) 2 used in H. Święcicki University Hospital, Poznań University of Medical Sciences 


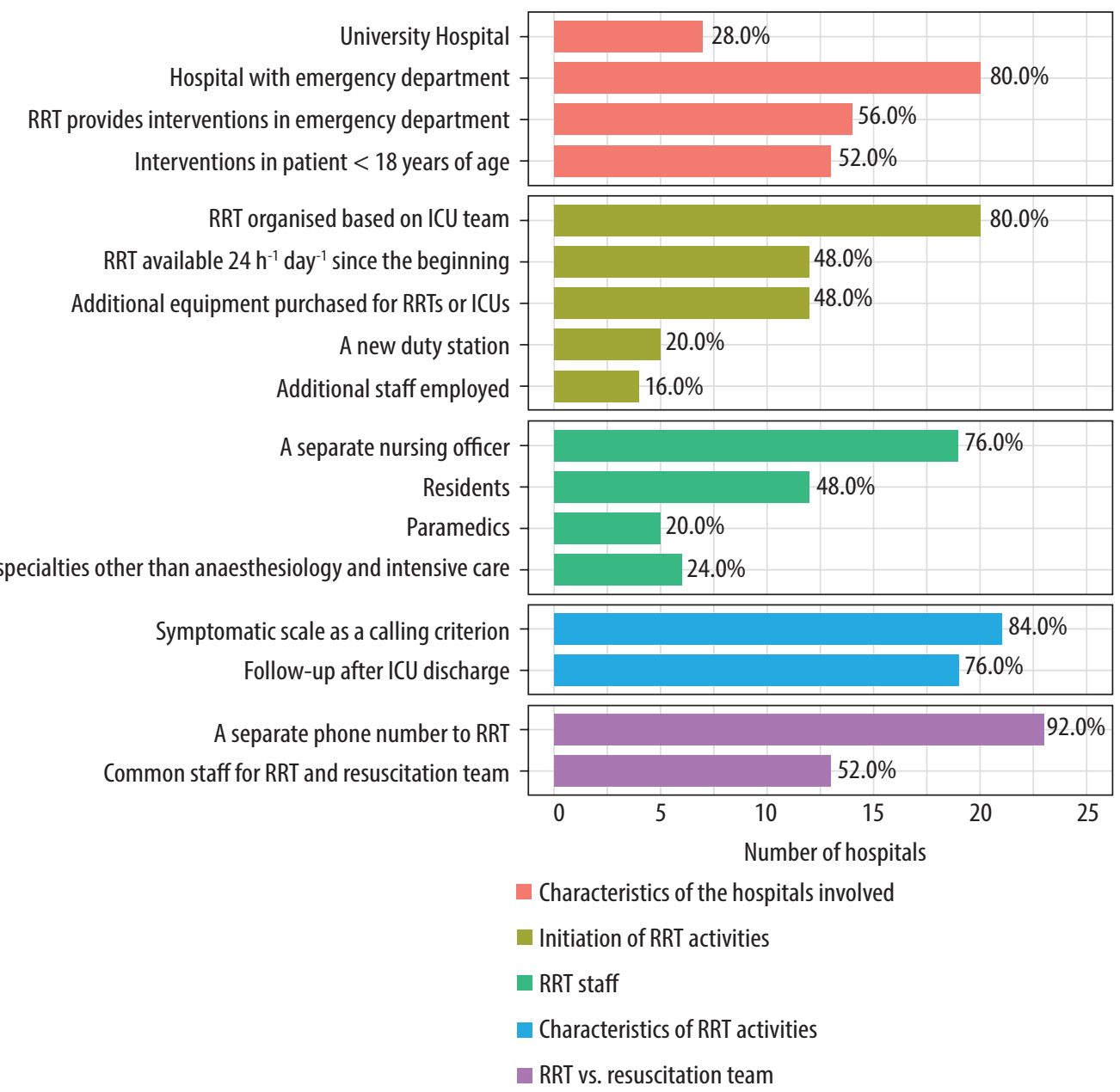

FIGURE 2. Results of the questionnaire carried out in the hospitals involved in the pilot program of rapid response team (RRT) implementation in Poland

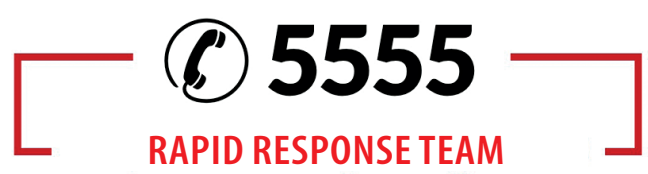

CALL RRT WHEN YOU ARE SERIOUSLY CONCERNED ABOUT THE PATIENT'S CONDITIONS OR YOU NOTICE A SUDDEN CHANGE IN:

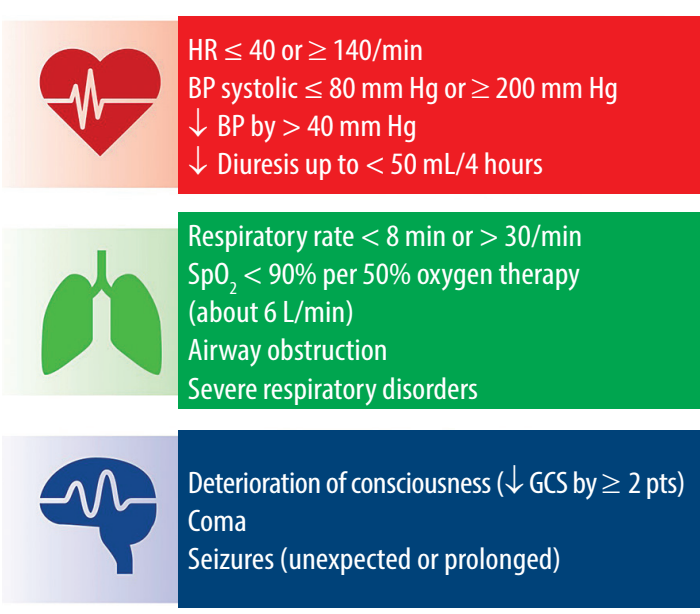

FIGURE 3. A leaflet presenting the rapid response team calling criteria (symptomatic scale)
3. The NEWS2 system or some other scores enable active screening and early identification of patients whose conditions deteriorate. In hospitals which do not use similar solutions, an effective strategy may be to identify higher-risk patients during routine ward rounds conducted by physicians or nurses.

\section{THE ROLE OF NURSING STAFF IN THE WARDS CALLING FOR RAPID RESPONSE TEAM'S ASSISTANCE}

One of the assumptions of the project is to enhance the role of nurses by granting them authority to initiate the procedure of RRT calling. The skills of the personnel directly attending patients are extremely valuable and essential for efficient functioning of the RRT system. The opinions of this group were clearly audible during the first months following implementation. Involvement and enthusiasm of nurses and paramedics surpassed initial expectations.

Female and male nurses initiated the procedure of RRT calling, facing no significant communication barriers; moreover, no grudges or complaints of physicians or the RRT staff were noted. Every fifth request 
for help was made directly by nurses; in some hospitals, the percentage of calls made by nurses significantly exceeded $50 \%$. Moreover, in some hospitals the number of calls caused by difficulties in care of particularly demanding patients decreased after suitable trainings of the ward staff provided by the RRT regarding care of the central line or tracheostomy insertion sites. According to the expectations based on the experience of other countries, mutual education of the personnel of various wards is a significant added value of the introduction of the system to Polish hospitals [4]. However, excessive workload resulting from staff shortages is likely to eliminate the above and other benefits associated with RRTs. Therefore, institutional solutions are required - functioning of the RRT system cannot rely exclusively on good will and involvement of individuals.

\section{Conclusions}

1. The introduction of RRTs enhanced the competences of nurses by formalising the possibility to call for help in each case when the patient's condition suddenly deteriorates.

2. The introduction of RRTs improved the feeling of safety and comfort of work of nursing teams working in non-ICU-wards. The ongoing detailed questionnaire study is focused on this issue.

3. Interventions of RRTs contributed to mutual education of the interventional team and those requesting help.

4. A wide-spread shortage of nurses is one of the major impediments to proper functioning of RRTs.

\section{THE RAPID RESPONSE TEAM STAFF AND STRATEGY OF RESPONDING}

Due to legal regulations, the RRT has to include a physician-specialist. However, it does not mean that every RRT intervention requires the involvement of physicians. In case of some calls (e.g. request for help concerning a tracheostomy patient requiring non-invasive mechanical ventilation, too frequent alarms of devices, difficulties in providing a vascular access), a suitably trained nurse or RRT's paramedic can be sent to the ward; depending of the patient's condition and the extent of interventions needed, they can provide appropriate help on the spot or call for a RRT physician. Such a solution successfully functions in some hospital involved in the project and the literature data have confirmed its effectiveness and safety [5]. Moreover, the leading role of the nursing staff in RRTs has been a standard in many healthcare systems in the West [6].

Our initial observations have confirmed that the nursing staff can also be a pillar of RRTs in Poland. Nursing coordinators have spared no effort to ensure efficient functioning of the teams, both medi- cally and administratively. In every fifth hospital, the nursing staff is supported by paramedics normally working in hospital emergency departments. Since this group of health care providers is highly competent and experienced in managing patients in lifethreatening situations, their involvement should be considered during the implementation of RRTs in Poland.

Moreover, additional benefits are likely to result from including residents in RRTs, e.g. residents specialising in anaesthesiology and intensive care or some other speciality during their training in intensive care. The experience of the centres which decided to include residents in RRTs (half of the hospitals involved) has demonstrated that residents are able to support the nursing staff during interventions, simultaneously gaining valuable experience and skills for working under crisis conditions (Figure 2). The above observation is consistent with the available literature data [7].

Two conditions have to be met for the RRT to function efficiency, i.e. availability of equipment and drugs as well as formal approval to order a full range of procedures by a member of the RRT in strict cooperation with the ward team. The range of activities of the RRT is tailored to the patient's needs and may include diagnosis and treatment in the ward, transfer to an intensive monitoring station, another ward or ICU. On arrival of the RRT, the members of the ward staff attending the patient become automatically the members of the RRT. Therefore, the role of the RRT is first advisory (consultative) and the decisions are made together with the team placing the call. Only in cases where the common decision is not possible, the RRT takes over decision-making.

The vast majority of hospitals managed to determine the formal framework of RRT functions based on regulations of hospital directors (managers). In almost half of hospitals, $24 \mathrm{~h}$ availability of the RRT was decided from the very beginning. Contrary to the initial concerns, we did not observe any systemrelated communication or competence difficulties. Undoubtedly, such difficulties occurred yet they were not troublesome enough to hinder the everyday work of the teams. There were many positive opinions about trainings in hospitals, particularly those focused on communication and conflict-solving skills, which also in future will be the basis of RRT functioning. Moreover, we should be prepared for possible formal-legal challenges, which the hospitals joining the program are likely to face in the nearest future. During the seminars summing up the first part of piloting the project, the issues connected with legal responsibilities of RRT physicians in cases of severe adverse events and the necessity 


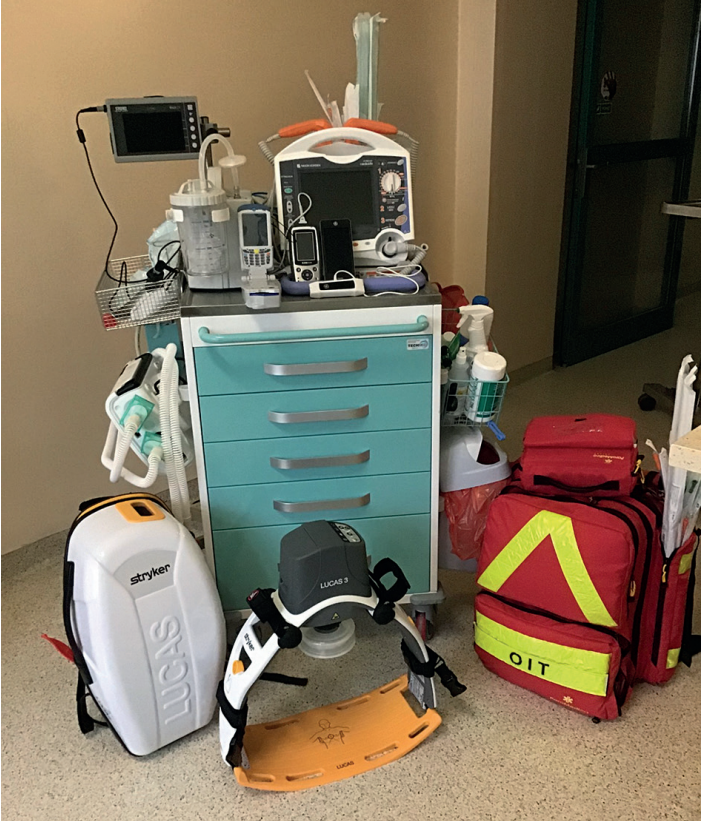

FIGURE 4. Equipment of the Wrocław rapid response team

to protect the entire hospital premises were debated. Large-scale consultations will be needed to find the optimal solutions at the system level. One of the priorities should certainly be informatisation, which will reduce the administrative workload of the personnel (already substantial) and directly increase the effectiveness of such activities as placing orders for procedures in the system or observation of patients after RRT interventions. Some hospitals managed to introduce efficient IT solutions enabling the harmonisation of medical documentation prepared by RRTs, which considerably reduced the administrative workload of the teams.

Several possible models to equip the RRTs have been found. Depending on the available hospital devices, the equipment of RRTs starting the intervention varies; some do not need any additional equipment and use the resources available in the individual wards, others take carts or cases designed for this purpose (Figure 4). Moreover, some solutions specific for given units were applied, e.g. routine use of an ultrasonography or a point-of-care critical parameters analyser.

Prior experience has demonstrated that the individuals placing the calls are well prepared for active cooperation and can support RRTs from the very beginning of interventions - they prepare medical records of patients, competently collect and provide the most relevant data concerning the patient's health condition. Each call is an opportunity to widen the specific skills of physicians and nurses less experienced in managing emergencies (acute conditions). The RRT coordinators were frequently provided with positive feedback from younger col- leagues working in other wards about the need to increase the availability of RRTs in their hospitals. Noteworthy, the system does not currently provide 24-hour services in all the hospitals involved, which is another consequence of inadequate funding and staff shortages (Figure 2).

\section{Conclusions}

1. Depending on demands and possibilities, the first individual responding to the call may be a female or male paramedic, as well as a nurse or a physician.

2. During interventions, the RRT has the competences of the staff of the calling ward while the nurses and physicians attending the patient in the ward become full members of the RRT.

3. Our aim should be to ensure full-time services of RRTs (24 h a day, 7 days a week) in all hospitals, although shorter services can be accepted due to organisational issues during the implementation period.

4. Possible inclusion of Emergency Department paramedics in the interventional RRT is worth considering.

5. To formulate the optimal legal framework for RRTs, large-scale consultations and appropriate decisions at the system level are required.

6. The dedicated technological solutions aimed at reducing administrative workload of the personnel and facilitating clinical decision-making under the conditions of staff shortages should be gradually introduced.

\section{COMMUNICATION}

Good communication is essential at all stages of RRT functioning. Firstly, an individual notyfing RRT should be able to effectively convey the most important information about the patient's condition to the RRT member. None of the hospitals involved reported any difficulties in this aspect - about $70 \%$ of centres decided to routinely use the SBAR protocol (situation, background, assessment, recommendation) at the stage of implementation [1]. Secondly, to ensure harmonious cooperation of the teams with the ward staff, an attending physician should be informed about the situation simultaneously with or prior to the call for RRT assistance, which will enable to build the partner relationship between the interventiondelivering and calling teams.

The cases of calling for the RRT by the nursing staff without prior notice to the attending physician, which may occur e.g. at surgical wards when all physicians are urgently needed in the operating room, were positively received. During seminars, all participants were directly asked about possible conflicts resulting from the calls, in which attend- 
ing physicians were exceptionally "neglected" - no such cases were reported. Attending physicians appreciated the RRT assistance in their absence. This is a good sign of further development of the early response system in Poland, indicating growing awareness of the benefits associated with common work of the entire group of health care providers for the sake of patients and with putting the rigid hierarchy aside in sudden life-threatening cases. The RRT can affect the safety of hospitalised patients only when all hospital health care providers are in a position to call for RRT assistance, if needed, without fearing of negative opinions and criticism.

\section{Conclusions}

1. A prerequisite for successful implementation of the program is effective communication and mutual trust between the wards calling for help and the RRT.

2. The SBAR protocol is a proven tool of effective communication when calling for assistance.

3. Irrespective of who calls for help, the treating team, including the attending physician, should be informed about sudden deterioration of the patient.

4. To develop and maintain appropriately high communication and teamwork skills under crisis circumstances, systematic trainings are required.

\section{MONITORING OF PATIENTS IN NON-INTENSIVE CARE UNIT WARDS}

According to the concept of an ICU without walls, the RRT can observe and take care of patients hospitalised in non-ICU wards. These are often patients at a high risk of cardiac arrest, requiring intensive monitoring and increased attention. When the RRT arrives, the patient is provided with the highest standard care - a physician experienced in medical emergencies and an intensive care nurse are present and necessary devices (infusion pumps, monitors of vital parameters) are available at the bedside. If the team manages to stabilise the patient and improve the patient's condition enough to avoid the transfer to the ICU, further care in the ward should be tailored to the patient's needs and staff skills. A similar situation is observed when the patient is admitted to the ICU based on the RRT decision, where his/her condition improves, and the patient is transferred to another hospital ward (Figure 2).

During our meetings, the issue of monitoring of patients at a high risk of deterioration was repeatedly discussed. It was unanimously decided that the number of intensive monitoring stations and enhanced surveillance units, like high-dependency and step-down units in Western countries, should be quickly and markedly increased. Otherwise, the benefits associated with the presence of the ICU or RRT in the hospital are likely to dissapear as further adequate care of patients will be infeasible.

The issue of formalising the observation of patients immediately after discharge from the ICU remains open. Depending on the model adopted, the RRT could actively support the ward staff over 24 or 48 hours following the transfer, thus ensuring a safe transition from intensive care to routine care. Based on previous experience, it seems appropriate to mark such patients in the IT system (or on a board designed for this purpose and placed at the location of RRT), according to the severity of patients conditions and the extent of requirements, like in the Emergency Departments (colours denoting how urgent the provision of assistance is). The above strategy is yet another element that can really reduce the incidence of ICU re-admissions, thus significantly reducing the hospitalisations costs. In some hospitals, the effects of introducing such strategies were spectacular as the number of re-admissions virtually decreased to zero. Given the significant shortage of intensive care beds in our country, the benefits resulting from such solutions can hardly be overestimated.

\section{Conclusions}

1. The number of intensive monitoring stations in Polish hospitals should be quickly increased and more equipment for monitoring vital signs should be systematically and continuously added.

2. Monitoring of patients after discharge from the ICU should reduce the incidence of ICU re-admissions, maximising the benefits associated with the RRT activities.

\section{THE SCOPE OF RAPID RESPONSE TEAM ACTIVITIES - ADDITIONAL INTERVENTIONS}

The major role of RRTs is to aid patients whose conditions suddenly deteriorate. There are cases, however, in which the RRT does not undertake actions to intensify the therapy, realising that further escalation of treatment will not be beneficial for patients. The experience of Western countries has demonstrated that discussions among RRT members concerning prognosis, clinical condition-grounded futile care (decisions to abandon chest compressions, defibrillation, mechanical ventilation) and end-of-life care may be of crucial importance from the point of view of patients' dignity and respect for the values that patients and their families believe in $[8,9]$. This difficult RRT-related issue has been continuously debated (although not in connection with paediatric hospitals), which indicates a vital need to raise awareness of futile care. During internal discussions, the most common opinion was that such con- 
versations with patients and their families should be carried out by the staff directly attending patients, most preferably prior to sudden deterioration of the patient's condition. Given that in practice the decisions about futile care are not always discussed earlier by the treating team (due to unpredictability of such situations, lack of formal trainings and particular complexity of the problem), there might be some cases in which the RRT together with the ward staff is involved in making these difficult decisions during interventions. In such situations, the role of the RRT is to create the conditions favourable for candid talks concerning restrictions in therapeutic interventions and futile care.

Depending on the number of calls and interventions in deteriorating patients, the members of some RRTs successfully supported the ward personnel by providing anaesthetic consultations, carrying out elective implantations of central catheters, anaesthetising patients outside the operating suite or ensuring transportation of severely ill patients. Nevertheless, it's worth stressing that the above activities should not routinely belong to the basic tasks of RRTs. Whether they are going to be included in the scope of RRT duties in the future or otherwise depends on the adopted model of functioning and financing of the rapid response system in Poland. At present, mainly ICU physicians and nurses work in RRTs, although single centres successfully selected and employed the members of the emergency department staff or the operating room. In about 50\% of cases, despite the presence of the RRT with its own procedure of calling and separate telephone number, the same personnel fulfilled the functions of the RRT and the resuscitation team (Figure 2).

\section{Conclusions}

1. The main tasks of RRTs are to take care of deteriorating patients and to follow up patients discharged from ICUs (e.g. routine, daily follow-ups over the first $48 \mathrm{~h}$ after ICU discharge).

2. The issues regarding the goals of treatment, limitations of some therapeutic interventions and futile care were relatively often discussed by RRT members during interventions. Importantly, the extent of interventions and potentially futile therapy should be mainly discussed with patients and their families by the attending team, preferably before the emergency intervention is needed. Noteworthy, the RRT members are better skilled and experienced in this regard.

3. Whether the RRT should have additional functions depends on the adopted staffing policy and workload of teams connected with their basic duties and responsibilities.

\section{SUMMARY}

The above paper, belonging to a series of publications on the implementation of RRTs in Poland, was prepared to share our experience gathered during one year of observations. The development of the RRT system exceeded the original expectations of the team responsible for project planning; most of the initial concerns proved vain. The flexibility in forming local RRT frameworks and support for individual solutions resulting from the specificity of a given centre were essential for successful implementation of the project. The grassroots initiative was triggered, which resulted in an array of activities aimed at a common goal - improving the quality of care and increasing patient safety. We do hope that our observations will prove useful for the existing teams and the centres which are about to consider the implementation of similar systems.

\section{ACKNOWLEDGMENTS}

1. Financial support and sponsorship: Co-financed by the European Union within the European Social Fund.

2. Conflict of interest: none.

\section{REFERENCES}

1. Szczeklik W, Czarnik T, Czuczwar M i wsp. Zespoły wczesnego reagowania - szybka pomoc w stanach nagłych w szpitalu. Część II: wdrażanie systemu ZWR w Polsce. Med Prakt 2018; 10: 113-122.

2. Friman O, Bell M, Djärv T, Hvarfner A, Jäderling G. National early warning score vs rapid response team criteria - prevalence, misclassification, and outcome. Acta Anaesthesiol Scand 2019; 63: 215-221. doi: 10.1111/aas.13245.

3. Szczeklik W, Jaeschke R, Kutaj-Wąsikowska H. Zespoły wczesnego reagowania - szybka pomoc w stanach nagłych w szpitalu. Część I: koncepcja oraz efekty działania zespołów w szpitalach na świecie. Med Prakt 2018; 9: 120-124.

4. Salvatierra GG, Bindler RC, Daratha KB. Rapid response teams: is it time to reframe the questions of rapid response team measurement? J Nurs Scholarsh 2016; 48: 616-623. doi: 10.1111/jnu. 12252.

5. Garry L, Rohan N, O'Connor T i wsp. Do nurse-led critical care outreach services impact inpatient mortality rates? Nurs Crit Care 2019; 24: 40-46. doi: 10.1111/nicc.12391.

6. DeVita MA, Bellomo R, Hillman K i wsp. Findings of the first consensus conference on medical emergency teams. Crit Care Med 2006; 34: 2463-2478. doi: 10.1097/01.CCM.0000235743.38172.6E.

7. Butcher BW, Quist CE, Harrison JD, Ranji SR. The effect of a rapid response team on resident perceptions of education and autonomy. J Hosp Med 2015; 10: 8-12. doi: 10.1002/jhm.2270.

8. Downar J, Rodin D, Barua R i wsp. Rapid response teams, do not resuscitate orders, and potential opportunities to improve end-of-life care: a multicentre retrospective study. J Crit Care 2013; 28: 498-503. doi: 10.1016/j.jcrc.2012.10.002.

9. Tam B, Salib M, Fox-Robichaud A. The effect of rapid response teams on end-of-life care: a retrospective chart review. Can Respir J 2014; 21: 302-306. doi: 10.1155/2014/393807. 


\section{Appendix}

\section{RRT LEADERS IN PILOT HOSPITALS}

Bydgoszcz - Mirosław Dobrowolski, Katarzyna Walkowiak, Danuta Pilch; Końskie - Wojciech Gola, Danuta Fatek; Ciechanów - Jacek Milecki, Violetta Matla; Poznań - Bronisław Baranowski, Honorata Troszczyńska; Polanica Zdrój - Henryk Szlemp, Renata Pluta; Katowice - Łukasz Krzych, Piotr Czempik, Mariusz Hoffman, Łukasz Nawotka, Żaneta Jastrzębska, Ewa Rogula, Beata Świrk, Agnieszka Szewczyk, Grzegorz Szpyrka; Lębork - Agata Karpik, Anna Musianowicz, Kamila Miotke; Szczecin - Michał Marcinkowski, Maria Smalec, Zenon Czajkowski, Sławomir Cyprys; Poznań - Agata Gradys, Sylwia Zdrojowa, Michał Burszewski, Krzysztof Pietrzkiewicz, Sylwia Miętkiewicz; Wrocław - Piotr Borecki, Agnieszka Kata, Dawid Łyś; Wrocław - Waldemar Goździk, Tomasz Skalec, Ewa Szewczyk, Elżbieta Ostrowska, Tomasz Ramuś, Izabela Witczak; Warsaw - Elżbieta Baum, Agnieszka Sosnkowska, Agnieszka Bartczak; Lublin - Andrzej Biłan, Anna Borowiec; Olsztyn - Dariusz Onichimowski, Hanna Taraszkiewicz, Joanna Myszkowska; Rybnik - Andrzej Pluta, Zofia Kowalczyk, Katarzyna Muszak; Brzesko - Paweł Dobosz, Iwona Wołos, Katarzyna Chmielarz; Zabrze - Jacek Karpe, Joanna Buczak-Molicka, Maciej Przybyła, Ewa Wąchowska, Iwona Osińska, Szymon Białka; Opole - Tomasz Czarnik, Adrianna Mazurkiewicz-Fornalik, Maria Grzeczna; Gorlice - Monika Sikorska-Górecka, Maria Boruch-Łoś, Danuta Kasprzak; Bochnia - Dariusz Para, Aneta Średniawa, Joanna Pechcińska; Białystok - Mariola Tałałaj, Elżbieta Sienkiewicz; Olsztyn - Krzysztof Narkun; Proszowice - Marek Bernaś, Katarzyna Krawiec, Bożena Knap; Zamość - Tomasz Kraczkowski, Andrzej Mielcarek, Renata Rogala, Urszula Taczala; Łódź - Waldemar Machała, Łukasz Sadowski, Justyna Kasznia.

\section{HOSPITALS INVOLVED IN THE PROJECT:}

1 - Independent Public (in Polish- SP) Regional Hospital in Szczecin

2 - Independent Public Specialist Healthcare Facilities (in Polish - SP ZOZ used further on) in Lębork

3 - Regional Specialist Hospital in Olsztyn

4 - S. Popowicz Regional Specialist Children's Hospital in Olsztyn

5 - L.Zamenhof University Hospital in Białystok

6 - H. Świecicki University Hospital, K. Marcinkiewicz Poznań University of Medical Sciences

7 - HCP Medical Centre, Ltd

8 - F. Łukaszczyk Oncology Centre in Bydgoszcz

9 - Regional Specialist Hospital in Ciechanów

10 - J. Popiełuszko Bielany Hospital, SP ZOZ

11 - Specialist Medical Centre, Joint-stock Company in Polanica Zdrój

12 - J. Mikulicz Radecki University Hospital in Wrocław

13 - T. Marciniak Lower Silesia Specialist Hospital - Centre for Emergency Medicine

14 - Central University Hospital, Medical University of Łódż

15 - ZOZ in Końskie, St. Lukasz Specialist Hospital

16 -St. John of Dukla Oncology Centre of the Lublin Region

17 - St. Pope John Paul II Regional Hospital in Zamość - Regional Specialist Hospital in Zamość

18 - SP ZOZ, University Hospital in Opole

19 -SP ZOZ, Regional Specialist Hospital no. 3 in Rybnik

20 - S. Szyszko University Hospital no. 1, Medical University of Silesia in Katowice

21 - K. Gibiński University Clinical Centre in Katowice, Medical University of Silesia in Katowice

22 - SP ZOZ in Prochowice

23 - SP ZOZ in Brzesko, L. Rydygier District Hospital in Brzesko

24 - SP ZOZ in Bochnia - District Hospital in Bochnia

$25-\mathrm{H}$. Klimontowicz Specialist Hospital in Gorlice 